\title{
Design and Implementation Path of Undergraduate Talent Training Program for Design Majors from the Perspective of Teaching Management
}

\author{
Qian Zhang ${ }^{1, *}$ and Wei Chang ${ }^{1}$ \\ ${ }^{1}$ School of Art and Design, Beijing Institute of Fashion Technology, Beijing, 100029, China \\ *Corresponding author. Email: zhangqianbj@126.com
}

\begin{abstract}
In order to further enhance the scientific, effective and forward-looking talent training program, this work focused on the design major and put forward the concept of "design research and development" talent training program from the perspective of teaching management. The project management methodology and tool set were applied to make overall planning and fully coordinate the relevant elements. Also, the talent training mode and curriculum system were systematically constructed and upgraded to ensure the effective implementation of the training path.

Keywords: Talent training; Training program; Teaching management; Design research and development
\end{abstract}

\section{INTRODUCTION}

One of the important social functions in colleges and universities is talent training, and the training objectives, graduation requirements and training process are condensed in the talent training program. As the basic program of undergraduate teaching, the talent training program in colleges and universities is the premise of comprehensively promoting the connotation construction of the school, and it is also the guidance for the implementation of all teaching and student training work. It is not only the embodiment and transformation of teaching reform achievements, but also the active strategy of education management innovation in production itself. Simultaneity, the training program is the most concentrated reflection of a major, a teaching department and a school in the teaching proposition, which reflects the future and foresight of education and teaching $[13,16]$.

The classification structure, discipline boundary, knowledge production mode and learning form of human knowledge system have been adjusted greatly in the $21 \mathrm{st}$ century due to profound changes in production patterns. In this context, design colleges and universities need to redesign the organization and update the concept of education and teaching. Taking learners as the center, they should make overall planning and fully coordinate the work focus and change elements. Simultaneously, the talent training mode and curriculum system should be systematically constructed and upgraded, and the effective path of students' academic growth should be innovated and developed. Based on the talent training mode, it needs to deeply dig down and systematically sort out and reconstruct in the operation mechanism and quality assurance mechanism of the training mode. The training scheme and guarantee system with the ability to develop the future should be designed and developed to cope with the systematic challenges that have substantial impacts on education, and the effective form of design education should be found in time to adapt to the tendency of the new era.

Accordingly, there are some issues in the formulation process, participants and management methods of the current talent training program, and the scientificity needs to be enhanced. First, the process of talent training program is usually one-way. The Academic Affairs Office publishes the requirements for the formulation of talent training program, and then the second-level teaching units formulate specific professional talent training programs. After the preliminary scheme is reviewed by the secondlevel teaching unit, it will be summarized and submitted to the Academic Affairs Office for review. Finally, it will be uniformly reviewed by the academic committee of the school and submitted to the principal in charge for approval before implementation. Second, the main body of personnel involved in each link is limited within the organization, and the scope is not wide enough. On the one hand, decision-making is limited by the breadth of personal knowledge, and on the other hand, there is no mechanism for smooth information and broad consensus. At the same time, there is a conflict between the administrative management mode and the academic training program. Third, the work system and audit link are not perfect. The formation and implementation of talent training program are equally important, thus forming a closed-loop system. The audit link is usually arranged in the final link, and the final review link is usually detailed and verified around the training target text, specific courses, hours, scores, etc., and thus it is difficult to put forward constructive suggestions fundamentally $[7,11]$.

On the other hand, the so-called "formulation" of talent training program usually feels that it is mainly document work or the implementation of this independent work, and 
it is a phased work behavior. Accordingly, the training program should be regarded as a program to guide the operation of the whole system. This work defines it as a "design research and development" training program, which is completely another operation mode and thinking mode. It is not only a text on paper, but also a methodology that can be introduced to carry out teaching reform step by step from different dimensions, and implement and improve the iterative system integration project.

\section{DISCUSSION ON THE KEY ISSUES OF DESIGN RESEARCH AND DEVELOPMENT TALENT TRAINING}

This part elaborates the importance and characteristics of the talent training program itself and puts forward the issues that have not been widely concerned about.

\subsection{External Display of Introvert Factors}

As one of the effective ways to quickly understand a certain specialty, the training objectives and curriculum settings in the talent training program reflect the foundation and direction of professional construction. It can also be said that the talent training program shows a series of internal collective reflection and measures such as teaching reform, curriculum construction, professional development, etc. Based on the educational concept of Outcome-Based Education (OBE) in engineering certification, the work put forward new challenges to the formulation of talent training plan and the achievement of talent training objectives. It requires more three-dimensional and comprehensive combing of the internal links, and requires the formation of a visible training plan from the abstract school running concept and professional thinking [3]

\subsection{Giving Consideration to Both Stability and Dynamics}

The talent training program is the foundation. It should not only maintain its scientific preciseness, but also timely respond to the development of the times and social needs, regularly evaluate, timely revise and improve [1]. Especially for design majors, the school is oriented to cultivate future oriented designers. Design majors are closely related to social production and life, attach equal importance to academic exploration and practical innovation, have the property of interdisciplinary knowledge, and are sensitive to the renewal and iteration of concepts and technologies. Therefore, the dynamic adjustment frequency of talent training programs should be relatively increased. At the same time, it is necessary to keep the relative stability of professional core according to the basic law of design discipline.

\subsection{Facing Uncertainty and Self Limitation}

Usually, a set of complete and unchangeable training program is applied to the four-year undergraduate training process. The design of research development training program is based on "certainty". For social development, certainty and uncertainty are both issues that need deep thinking. Is it possible to design the uncertainty of talent training mode and process, so that the uncertainty becomes the determination of future quality? All of these are the challenges of the times. All departments of colleges and universities are a cooperative partner and a common relationship on this issue. Uncertainty can also offer the necessary space for organizational learning and adaptation. At the beginning of designing research and development talent training program, it is based on limited people's limited understanding of social and professional development and their own limited experience. What kind of methodology and tool set should be imported to expand finiteness.

\subsection{Management Attribute of Talent Training Program}

Talent training program is also called teaching plan. The five major functions of benchmarking management are "planning, organization, command, control and coordination". Plan is the premise and foundation of other management functions, and permeates into other management functions. Organization support, resource coordination and quality control are also needed in the process of plan formulation, revision and implementation. The formulation and revision of talent training plan itself is a decision-making process. "Analyzing the situationclarifying the problem-formulating the plan-evaluating and revising-implementing fine-tuning" are all necessary steps, and any omission will make it less scientific. 


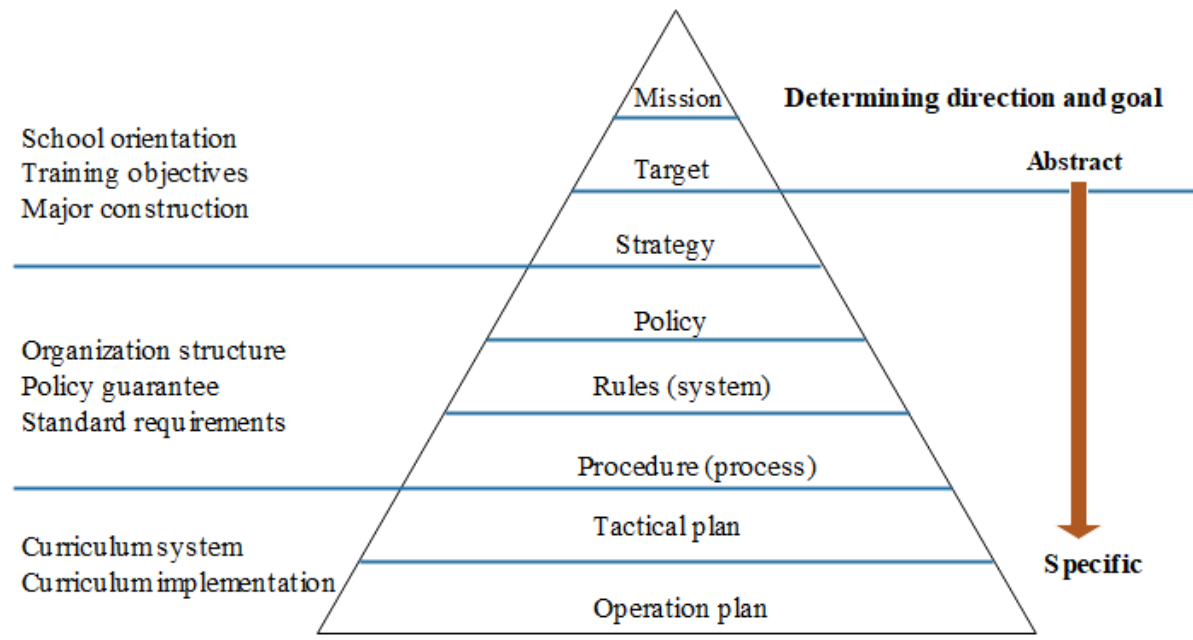

Figure 1. The corresponding relationship between the planning level of talent training program and other work

\section{THE IMPLEMENTATION PATH OF DESIGN RESEARCH AND DEVELOPMENT TALENT TRAINING}

This chapter combines the practical experience in the teaching reform process of the School of Art and Design, Beijing Institute of Fashion Technology in recent years, and discusses the possibility of facing the future.

\subsection{The Basic Process of Design Research and Development Talent Training}

At present, the explicit process of making and revising the talent training plan in colleges and universities is to issue the principle opinions of revising the talent training plan, and to standardize the credits, credit hours, credits and categories of general compulsory courses and public elective courses. Then, the secondary colleges organize and carry out full research, refer to the relevant professional training programs at home and abroad, hold internal seminars, and put forward suggestions for revision. Experts from other universities and industry units are invited to hold several rounds of demonstration meetings, which are approved by the academic committee of the college and submitted to the science and education index committee of the college for examination and approval before implementation.

From the perspective of each system, design research and development talent training is a process of reaching a broad consensus on the school-running philosophy. It is not only a means to implement the professional construction and teaching reform, but also the crystallization of achievements. Therefore, the basic path of talent training program design and development is formed: the necessity and feasibility analysis of talent training program adjustment (feasibility study analysis)-background investigation of reform (competition analysis)-expecting the effectiveness and important measures of teaching reform (user demand; product demand)-professional orientation and personnel training objective-curriculum system and content-curriculum realization-resource scheduling-quality control. In each link, the roles of different levels, such as school leaders, functional departments, academic experts, teaching managers, frontline teachers, students, society, etc., are fully mobilized to participate in the process. They can listen to opinions more widely and reach a broad consensus. At the same time, they can solve key issues at an early stage and achieve the whole process management.

In the process of design research and development, the PDCA cycle quality management concept is used to introduce the methods and tools of total quality management. Specialized personnel are responsible for the progress management and material archiving of the research and development process, and academic experts are responsible for the quality control of the stage and final results. At the same time, the combination of internal and third-party monitoring is adopted to scientifically monitor and evaluate the quality of talent training, improve the quality monitoring and evaluation system, and form a quality control closed loop to test and revise the initial goal setting. 


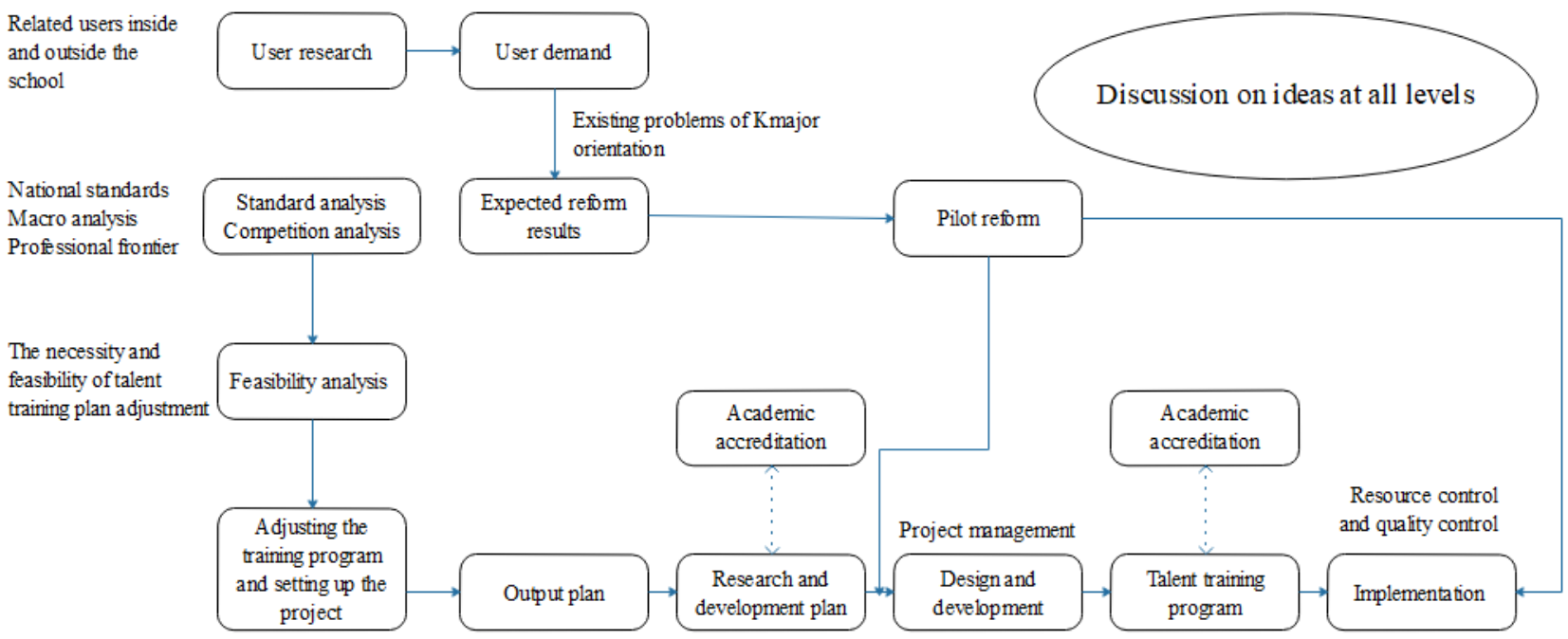

Figure 2. Basic design and development path of talent training program

\subsection{The Factor Analysis of Design Research and Development Talent Training}

The formation of talent training program is the result of multiple factor interaction, especially in the first link of design and development. In feasibility study analysis and user needs analysis, the information and data need to be collected are complex and interrelated, involving social needs, government requirements, teachers' teaching, students' learning, etc. Therefore, it is necessary to obtain as much quantifiable and non-quantifiable information as possible from internal and external sources, and make relatively optimal decisions after realizing the integration and visualization of information. For example, these decisions are learning behavior organization mode, the integration of tutorial system, class system and credit system, and the change of knowledge organization mode in the post epidemic era [6].

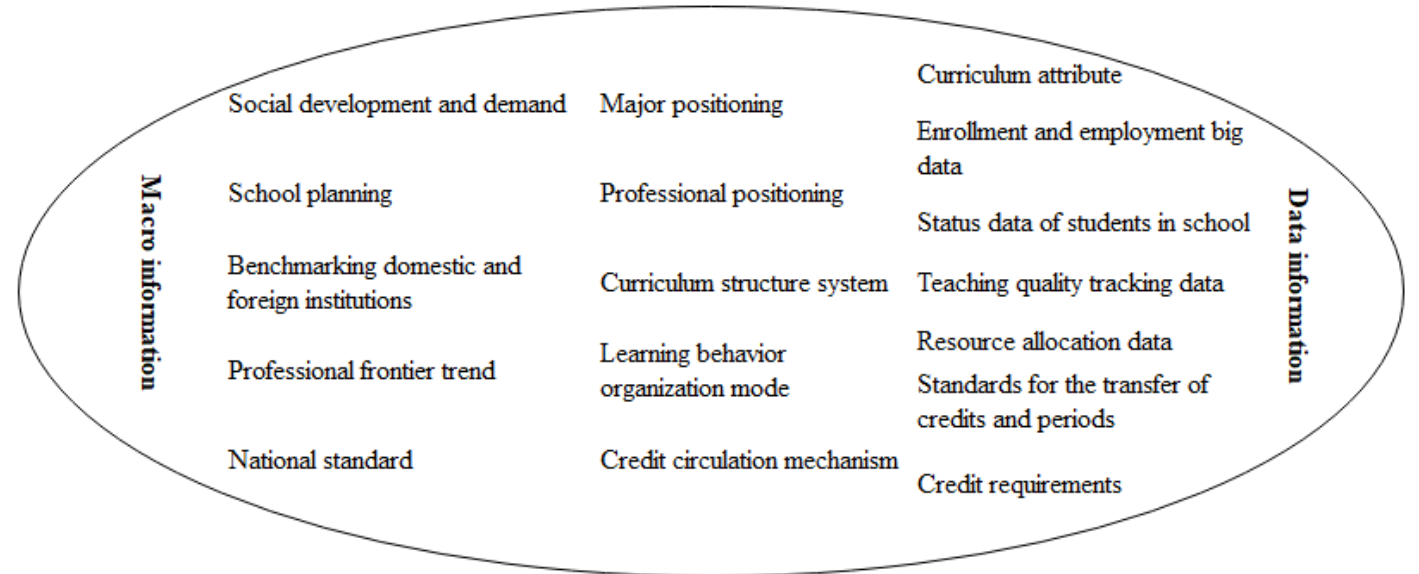

Figure 3. Information elements of talent training program design and research development

Due to the opportunity cost of trial and error in talent training program affects students' individual development, the college proposes the idea of introducing intelligent tools. Using educational innovation trend insight and scenario planning method tools, machine learning and data mining technology to conduct preliminary knowledge management of talent cultivation program on social trends, form trend insight data pool, and write talent cultivation target proposal. Based on the macro and overall grasp of frontier trend information, systematic modeling and parameterization setting are carried out for factors such as training mode, course attribute and course structure system, organization mode of teaching and learning behavior, student size and learning resource allocation demand, big data utilization of enrolment and employment, etc. Consequently, the digital sandtable rehearsal for teaching reform and talent training mode reform is realized, and the digital technology enables the risk management and scientific decision-making of systematic teaching reform in the generation stage of training scheme. 


\subsection{The Outcomes of Talent Training Program}

The final output of design research and development talent training program includes explicit results and implicit results. Explicit results are solidified in the form of text and delivered for application. However, the hidden achievements formed in the process are more important, including clearer professional orientation, the consensus of the whole staff on the teaching proposition, etc. By introducing advanced methodology and tool set, the hidden achievements can be visualized and played more effectively.

\subsubsection{The explicit output of talent training program (text content)}

Talent training programs are usually delivered in text, including training objectives, graduation requirements, curriculum system, credit hours distribution statistics.

For a school or a college, the training goal guided by the training plan is almost the most important "text", which is the text of guiding system action and allocating resources, connecting "college mission-system questioning-practice exploration". The content of the text includes the professional orientation, the overall training objectives, graduation requirements and the degree of achievement, which reflects the era competency of talent training.

The construction of curriculum system is based on the choice of learning organization mode, and the comprehensive credit system is explored and innovated by integrating the advantages of different learning organization modes such as the tutorial system, class organization system, credit system, etc. For the projects of multiple talent training paths and intercollegiate exchange projects in colleges and universities, the integrated credit system of tokenization and open source is expected to be able to innovate the circulation mechanism of credits. Therefore, new learning mechanisms such as innovative global inter-city learning, innovation and entrepreneurship driven learning, lifelong learning, etc., are supported, and imagination space is provided for future learning forms and campus forms of the college and university.

The curriculum system includes the choice of professional core curriculum, several curriculum modules and their relationship, and the relationship between curriculum arrangement and content and the achievement of training objectives [4].

The current text format is basically the listing of curriculum information, or by semester or by curriculum system. It includes the course name, class hours, credits, course attributes (compulsory, elective, public), assessment methods, semester, etc. The above scattered information is difficult to see how the training objectives are reflected in the curriculum system. However, the users of the talent training program mainly include teaching managers, teachers, students, and other groups who pay attention to the major of the college. They all need to see the logical relationship behind the curriculum system in order to truly clear and better ensure the effective achievement of the training objectives.

\subsubsection{Implicit output of talent training program}

The research and development of talent training program is a process of re-refining and analyzing the professional orientation. The college tries to develop a tool set to answer the professional identification more scientifically and effectively. According to Fig. 4, the following questions need to be asked: first, what is the core of a major (clarifying the core curriculum from the perspective of professional identification and irreplaceable)? Secondly, what abilities need to be developed in the face of the changes and expansion of the application field (adding knowledge content of application level and professional depth level)? Third, where is the boundary of specialty (exploring the possibility of cross cooperation among majors, and producing courses and training methods of horizontal connection and expanding thinking width in the face of new technology, new needs and new concerns) [5]?

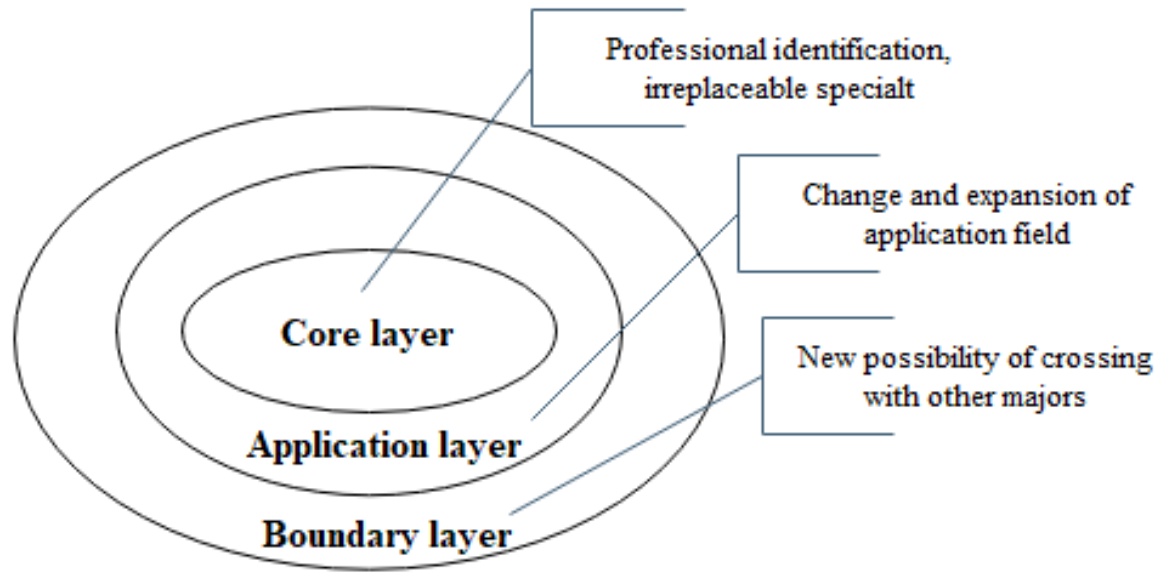

Figure 4. Key elements model of professional identification 
Accordingly, a complete talent training plan has been formed after several rounds of ideological discussions. At the same time, the four-year curriculum structure mode, the logical relationship between courses, the way of arranging courses, and the main teaching method of each course (the basis of forming the syllabus) have also been clarified. These achievements of teaching management, curriculum system and curriculum content jointly determine the implementation effect of the training program, forming the whole process quality control from plan to implementation.

3

\section{4}

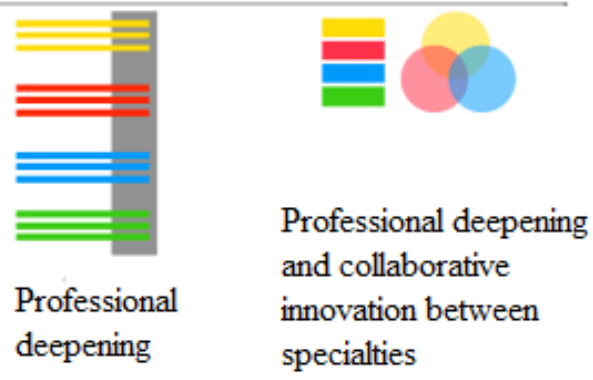

Figure 5. Structure pattern of four-year undergraduate courses in School of Art and Design, Beijing Institute of Fashion Technology

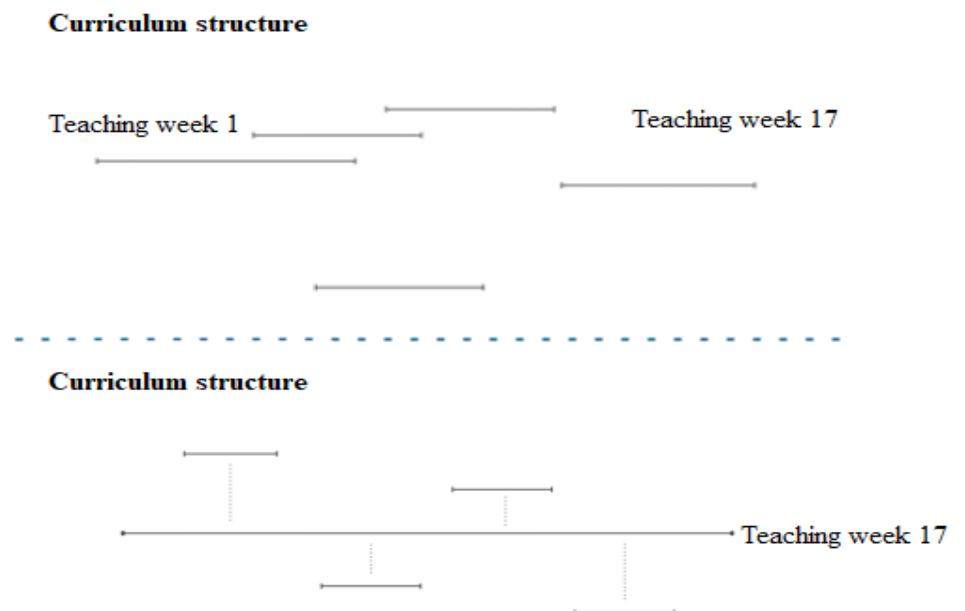

Figure 6. Two main course structure ways of class scheduling for design majors

The following are some common teaching methods of design courses at present. For some courses, it is not only a choice of one method, but also a combination of two or more methods. According to the specific teaching situation, there are some choices and emphases.

$$
\text { Course teaching Case analysis Copying Lecture course }
$$

Artistic creation

$$
\text { Investigation and analysis }
$$

\section{Work camp}

Practical operation

Real project

Discussion course

\section{Seminar course}

Scene deduction

Collecting wind

Social practice

Field investigation

Figure 7. Various teaching modes of design class 


\section{CONCLUSION}

The classification structure, discipline boundary, knowledge production mode and learning form of human knowledge system have been adjusted greatly in the $21 \mathrm{st}$ century due to profound changes in production patterns. In this context, design colleges and universities need to make profound changes to cope with the systematic challenges that have a substantial impact on education. As the basic program of undergraduate teaching, it is of great significance to scientifically and effectively design research and development talent training programs. The requirements of engineering certification are gradually promoting the requirements of talent training program, which are student-centered, output-oriented and continuous improvement driven. Accordingly, this work explored the deep-seated problems of design professional talent cultivation from the perspective of teaching management. Based on the concept of project management and whole process quality control, this work combed the design research and development path, and explained the explicit and implicit output of talent training program, thus making the design research and development process more scientific and effective. At the same time, the consensus was widely gathered. The process and output were realized, and the deviation free quality control was implemented in the follow-up program implementation process.

Based on the empirical research background of School of Art and Design, Beijing Institute of Fashion Technology, the ideas of design education play a positive role in the construction of contemporary lifestyle under the community of human destiny and global vision. Learning innovation and design learning should become a contemporary lifestyle and social driving force. Using the design thinking method, the college is exploring the introduction of concepts and model tools in the fields of organizational transformation management, knowledge creation management, education trend insight and scenario planning. Based on the solid education and teaching practice in the past, the future oriented talent training program of design specialty should be designed and developed. It is necessary to carry out systematic research, design and development, break the barriers of fixed thinking, make the college level reforms form a systematic linkage and synergy, and form a "planning performance cycle-quality cycle-data cycle" [1]. The basic framework of university governance modernization at the college level should be explored to promote the sustainable development of the college in the future.

\section{ACKNOWLEDGMENT}

This work was supported by Beijing Education Reform Project: "Design the School of Design: Design and development of talent training system of the design majors towards future".

\section{REFERENCES}

[1] Ding Xiaochang. Self-learning Management in Colleges and Universities [M]. Jiangsu: Jiangsu Education Press, 2010: 2-35.

[2] Ministry of Education Teaching Guidance Committee for Higher Education Institutions. National Standards for Undergraduate Professional Teaching Quality in General Higher Education Institutions [M]. Beijing: Higher Education Press, 2000: 943-963.

[3] Xu Yinli. Development Path and Main Points of Higher Vocational Talent Training Program Based on OBE Concept [J]. Jiangsu Education, 2020 (92): 36-41.

[4] Deng Zhongmei. Professional Training Program and Industry Achievement Evaluation Research [J]. Science and Technology Wind, 2020 (23): 164-165.

[5] Yue Aichen. The Construction and Implementation of Professional Core Courses [J]. Beijing Education: Higher Education Edition, 2007 (3): 43-44.

[6] Wang Weilian. Discussion on the Establishment of Undergraduate Courses in Colleges and Universities [J]. Higher Education Research, 2003 (2): 78-81.

[7] Chai Hongmin, Li Xiuqin, Liu Jianzhan, et al. Theoretical Analysis on the Reform of Talent Training Mode and Training Program [J]. Journal of North China Institute of Water Conservancy and Hydroelectric Power: Social Science Edition, 2009 (3): 102-104.

[8] Zeng Dongmei, Huang Guoxun. The structural model of professional training programs in colleges and universities [J]. Jiangsu Higher Education, 2002 (3): 8991.

[9] Xu Guoqing. National Professional Teaching Standards and School Talent Training Plan [J]. Vocational Education Forum, 2017 (30): 1-1.

[10] Hou Hongling, Zhang Junfeng, Ren Zhigui, et al. Reverse Design Professional Talent Training Program Based on OBE Concept [J]. High Education Journal, 2018 (24): 167-169.

[11] Chen Mingxue. Thoughts on Perfecting the Management of Talent Training Programs in Colleges and Universities [J]. Education and Vocation, 2012 (3): 34-36.

[12] Wang Jianwu, Zhao Xu. The Formation Process and Reference of Applied Talent Training Programs in Developed Countries [J]. China Adult Education, 2020 (14): $72-74$. 
[13] Mao Weiwei. Analysis on the Undergraduate Talent Training Program Based on the Result-Oriented Concept [J]. Journal of Fuqing Branch of Fujian Normal University, 2020 (3): 96-102.

[14] Yang Zhe. Analysis and Design of Training Objectives and Training Specifications for Digital Media Majors [J]. Modern Educational Technology, 2012 (12): 80-83.
[15] Zhao Kai, Yuan Xiaoling, Yue Zhen. Experience Analysis on Innovative Talent Training in Foreign Universities and the Development of Creative Class with Chinese Characteristics [J]. Education Teaching Forum, 2019 (34): 6-9.

[16] Zhu Jiagui. Deepen the Reform of Ability-oriented Talent Training Model [J]. China Higher Education, 2015 (12): 35-37. 